\title{
Single-Stage Grid-Connected Flyback Microinverter Operating in DCM for Photovoltaic AC Modules
}

\author{
Turki K. Hassan, PhD \\ Electrical Engineering Department, \\ Faculty of Engineering, \\ Al-Mustansiriya University, \\ Baghdad, Iraq
}

\author{
Mustafa Abbas Fadel \\ Electrical Engineering Department, \\ Faculty of Engineering, \\ Al-Mustansiriya University, \\ Baghdad, Iraq
}

\begin{abstract}
In this paper, a single-stage grid-connected flyback microinverter is proposed. The proposed flyback microinverter has some advantages such as high voltage gain, high efficiency, low cost, small size, simple control and high power factor. The proposed system is used to connect the PV panel to the grid with achieving maximum Power Point Tracking (MPPT) control. The converter operates in DCM to inject a sinusoidal current into the grid with unity power factor. A complete system has been simulated using PSIM program. The simulation results are obtained to validate the system.
\end{abstract}

\section{Keywords}

Single-Stage, grid-connected, Microinverter, Flyback, DCM, MPPT.

\section{INTRODUCTION}

Fossil fuels have been widely used from the beginning of the industrial revolution. Combustion is needed, so as the energy stored in fossil fuels liberation. During this process, a release of emissions is unavoidable into the atmosphere. Moreover, extraction and transportation of fossil fuels cause environmental pollution along with serious consequences such as air pollution, global warming, soil degradation and water deterioration.

Due to problems of environmental pollution, protection the environment and the energy production become the major problems for human. Thus the development and application of clean renewable energy, like wind power, solar power, biomass, geothermal power, wave and tidal power, and nuclear power are getting more interest. Solar power will be predominant among them due to its reliability and availability [1].

A photovoltaic panel is a device that converts luminous energy into electric energy through the photoelectric effect. The electric energy is available at the terminals of the PV panel in the same instant that the sunlight reaches it, most of the electric equipment of standard use cannot connected directly, this because the generated current from the PV panel is continuous $(\mathrm{dc})$ and at low voltage (generally between 12 and 68 volts, depending on the technology used in the panel construction) and the majority of the equipment operates at alternating current (ac), at higher voltages [2]. This brings the need for power interface between the PV panel and the grid through power electronic converters or inverters or as called power conditioning inverter [3]. Flyback inverter, shown in Figure (1) is used to convert dc power from the PV panel into ac power and injecting ac current into the grid.

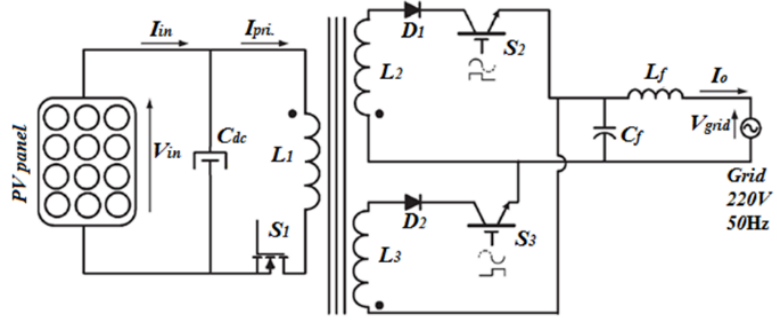

Figure (1): Flyback Microinverter

Inverters may be classified as single stage and two stage configurations as shown in Figure (2). Single stage inverters boost the input voltage and convert it into ac voltage in the same stage. Two stages inverters consist of two cascaded stages. The first stage is a boost dc-dc converter and the second one is an inverter. Single stage inverters have some advantages over two stage inverters; such as low cost and small size [4].
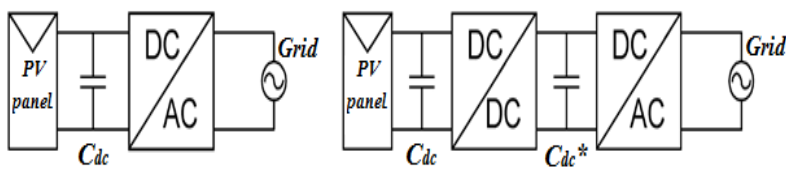

Figure (2): single stage and two stage configurations.

Typically, the grid connected PV systems may be required to either buck or boost the voltage depending on the available PV panel voltage. Usually, grid connected PV systems involve multiple power stages, with a dedicated dc-dc converter stage for MPPT and voltage level transformation. The multistage systems suffer of many disadvantages such as lower efficiency, larger size and higher cost. Therefore the modern day trend is derived towards single stage grid connected configurations because of their small size, low cost, high efficiency and high reliability. Clearly, the single-stage philosophy cannot afford a dedicated dc-dc converter stage for MPPT. Therefore, in single-stage grid connected PV systems, the sole power stage must achieve MPPT, boosting or bucking (if required) and inversion together [5]. The proposed inverter in this paper consists of flyback inverter with PWM modulation. The converter operates in the DCM to inject a naturally sinusoidal current into the grid with unity power factor.

The paper is organized in the following way. Section 2 presents analysis and operation of the proposed system and its principle of operation. Section 3 presents maximum power point tracking technique. Section 4 summarizes simulation results of the proposed system. Section 5 presents the conclusions. 


\section{THE PROPOSED INVERTER SYSTEM}

The flyback microinverter is shown in Figure (1). Its transformer primary side consists of switch $S_{1}$ being the main power switch and power decoupling capacitor. The secondary side of transformer consists of switches $S_{2}$ and $S_{3}$ which turned on and off in an appropriate manner to ensure an ac output waveform synchronized with the grid. $S_{2}$ is on and $S_{3}$ is off if it is needed for energy to be transferred to the ac output with a positive polarity and $S_{2}$ is off and $S_{3}$ is on if it is needed for energy to be delivered to the output with a negative polarity. The output capacitor can filter the output produced by the rest of the converter so that the appropriate final output is produced and fed to the grid.

Figure (3) shows the operation of this converter during a line half cycle is as follows: When the primary switch, $\mathrm{S}_{1}$, is on, the full PV panel input dc voltage is impressed across the transformer, thus putting energy into its magnetizing inductance and making its magnetizing current rise. When $S_{1}$ is off, the stored energy in the transformer's magnetizing inductance will transferred to the output, which is the grid. Since the output is ac, which means it is either transferred through $D_{1}$ and $S_{2}$ when the voltage output is positive or through $D_{2}$ and $S_{3}$ when the voltage output is negative. $S_{1}$ duty cycle should be made to vary throughout the ac voltage line cycle so that it is at its minimum when the ac voltage is at its minimum and it is at its maximum when the ac voltage is at its peak. As a result, the converter must be implemented with some control schemes that can track the ac grid voltage and synchronizes its operation to this voltage.

The basic principle that must be followed to ensure that the microinverter produces an appropriate ac output waveform is that the flyback transformer must be fully demagnetized before the start of the next switching cycle. If the converter's duty cycle is made to vary throughout the ac line cycle (small duty cycle for the zero crossing regions of the ac waveform, larger duty cycle for the peak regions) then a discontinuous ac current waveform can be produced at the secondary as shown in Figure (4) [6].

To ensure that the inverter operates in DCM

$$
t_{o f f \_p} \leq T_{s}-t_{\text {on_p }}
$$

Where $t_{o f f \_p}$ is the off time of $S_{1}$ in the switching cycle when the primary current reaches its peak value of $I_{p r i} p$ and $t_{o n \_p}$ is the on time of $S_{1}$ during the same switching cycle and can be expressed as

$$
t_{\text {on } \_p}=d_{p} T_{s}=\frac{d_{p}}{f_{s}}
$$

Where $f_{s}$ is the switching frequency and $d_{p}$ is the duty cycle.

The current in $L_{m}$ can drop to zero when $S_{1}$ is turned off and the energy that is stored in it is transferred to the output. When $S_{1}$ is turned off, the voltage across the transformer is the output voltage that appears across the secondary winding and is reflected to the primary. This voltage can be expressed as

$$
v_{\text {grid }}(t)=V_{\text {grid_p }} \sin \omega_{g} t
$$

Where $V_{\text {grid } \_p}$ is the peak value of output voltage and $\omega_{g}$ is the grid frequency in $\mathrm{rad} / \mathrm{sec}$. Considering this voltage reflected to the primary, the fall of current in Lm can be expressed as

$$
N v_{\text {grid }}(t)=L_{m} \frac{d i_{\text {pri }}(t)}{d t}
$$

Where $N$ is the turns ratio. So that $t_{\text {off }}$ can be expressed as

$$
t_{o f f \_p}=L_{m} \frac{I_{\text {pri_p }}(t)}{N V_{\text {grid_p}} p}
$$

To determine the turn off time $t_{\text {off } \_p}$ the peak primary current flowing through the flyback inverter $I_{\text {pri }}$ p needs to be determined. This can be done by considering the fact that the input dc voltage $V_{i n}$ is impressed on the transformer primary when $S_{1}$ is on. The rise in current when $S_{1}$ is on can be expressed as

$$
V_{\text {in }}=L_{m} \frac{d i_{p r i}(t)}{d t}
$$

Substituting (2) into this equation gives the following expression for $I_{\text {pri_ }} p$

$$
I_{\text {pri_p }}=\frac{V_{\text {in }} d_{p}}{f_{s} L_{m}}
$$

Substituting this equation into equation (5) gives,

$$
t_{o f f \_p}=\frac{V_{i n} d_{p}}{V_{\text {grid } \_p} f_{S} N}
$$

It can be seen from equation (8) that $t_{o f f \_p}$ dependent on various parameters. Assuming a fixed switching frequency $f_{s}$, these parameters are fixed except for peak duty cycle $d_{p}$ and turns ratio $N$. Values for $d_{p}$ and $N$ need to be chosen so that the converter remains in DCM. This can be done by considering the expression for DCM operation given in equation (1) and substituting equation (8) into this equation to get

$$
\frac{V_{\text {in }} d_{p}}{V_{\text {grid_p }} f_{S} N} \leq T_{S}-t_{o n \_p}
$$

Equation (9) can be rearranged to give the following expression for peak duty cycle

$$
d_{p} \leq \frac{1}{\frac{V_{\text {in }}}{N V_{\text {grid } \_p}}+1}
$$

The next step is to determine an appropriate value of magnetizing inductance $L_{m}$ that can store sufficient energy to be fed to the grid, for a rated output power Po. Once this has been determined, the final step is to confirm that the converter 
can operate with DCM with this value of $L_{m}$. The value of magnetizing inductance $L_{m}$ can be calculated using the following equation (6)

$$
L_{m}=\frac{1}{2} \lambda^{2} \frac{d_{p}^{2} V_{g r i d}^{2}{ }_{-} r m s}{f_{s} P_{o}}
$$

Where $\lambda=\frac{V_{\text {in }}}{V_{\text {grid_p }}}$

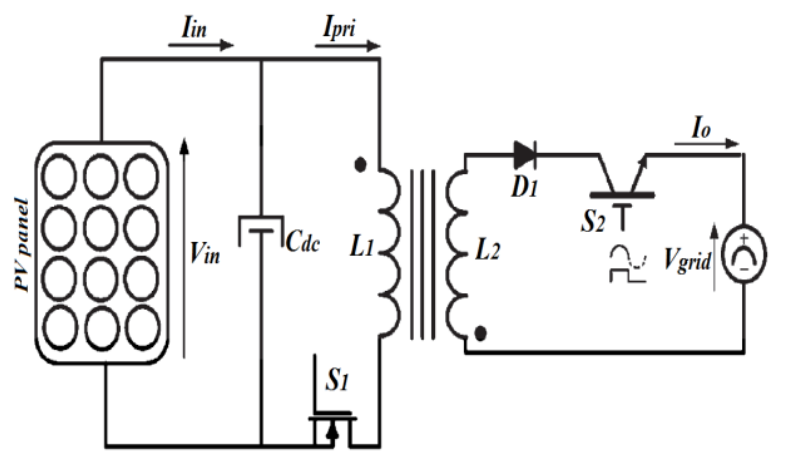

(a)

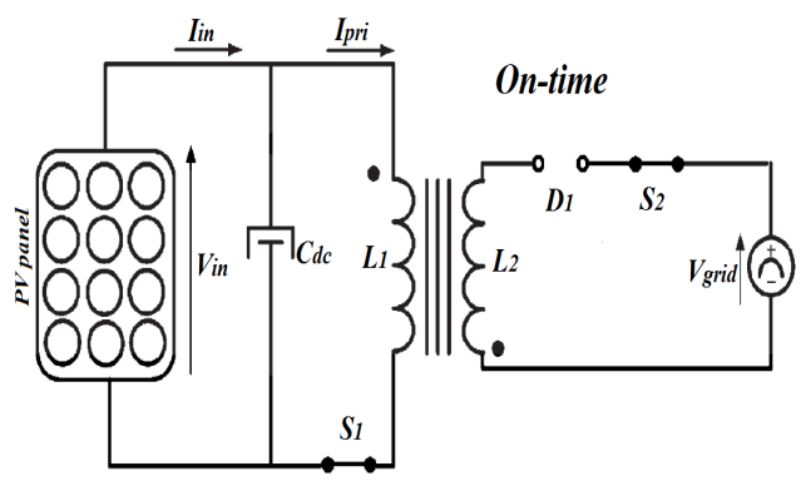

(b)

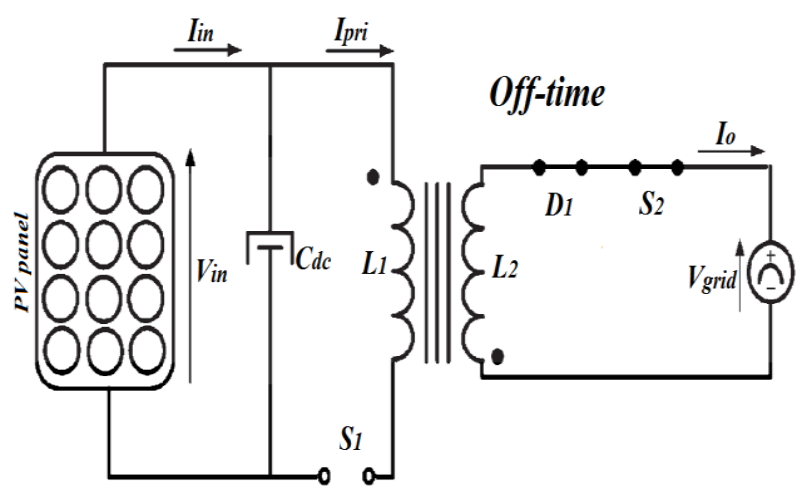

(c)

Figure (3): Equivalent circuit of the current source flyback inverter during a line half cycle. (a) Each line half cycle. (b) During $S_{1}$ on time. (c) During $S_{1}$ off time.

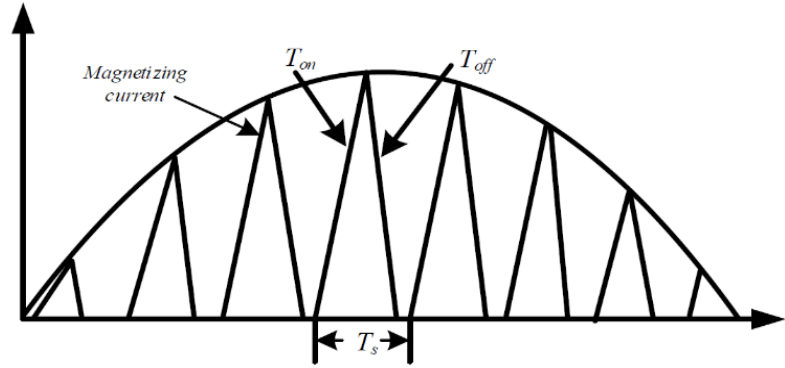

Figure (4): Discontinuous conduction mode of magnetizing current

Figure (5) shows typical waveforms for the flyback inverter. It can be seen that, as the gate pulse of switch $\mathrm{S}_{1}$ becomes high at $\mathrm{t}=T_{1}$ and the switch is turned on, the switch current, $I_{s l}$, rises and the voltage $V_{d s}$ across the switch $\mathrm{S}_{1}$ becomes zero.

At $T_{2}$, the switch is turned off, the current $I_{s l}$ cannot go to zero suddenly because inductance in the current path. Also the secondary diodes take some time to turn on, for the period $T_{2}-T_{3}$ there will be some voltage spike.

At $T_{3}$ the secondary diodes conduct and the stored energy in the transformer is transferred to the load. During this period there will be an additional reflected voltage $(N V o)$ across the main switch on top of input voltage.

As the secondary current goes to zero at $T_{4}$ there is no reflected voltage, hence the $V_{d s}$ will be same as $V_{i n}$.

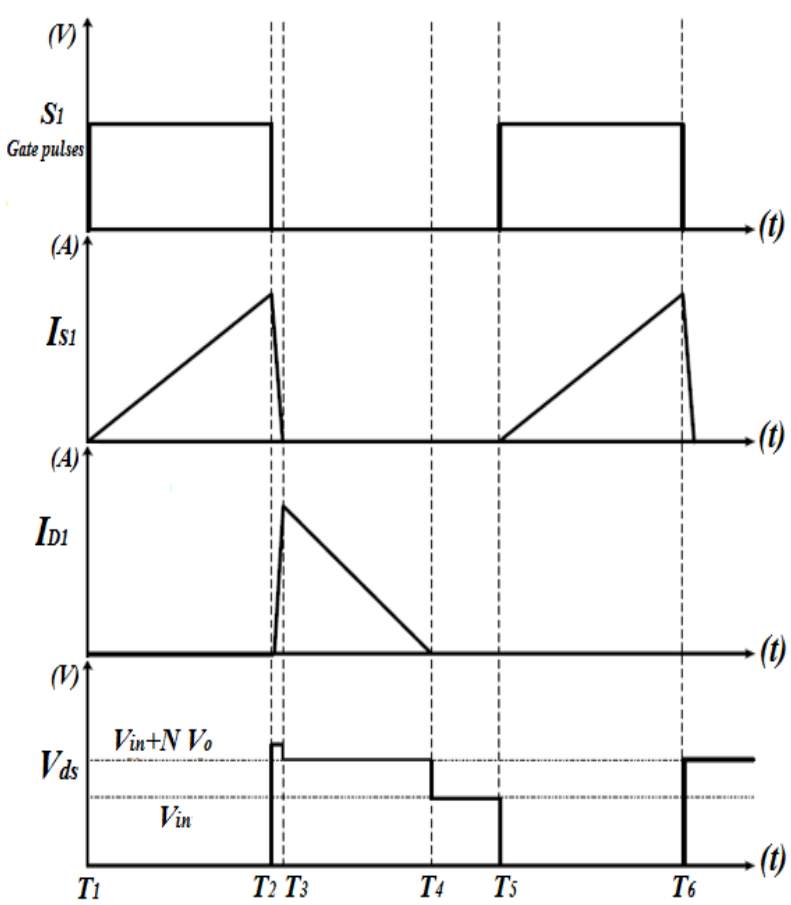

Figure (5): Typical operating waveforms of a flyback converter.

\section{THE PROPOSED CONTROL}

The proposed control is based on DCM operation. It requires the achievement of MPPT and unity power factor for the output current of the inverter in addition to boosting the input voltage into its required level. Figure (6) shows the schematic of the proposed system, as shown in the figure, grid voltage is sensed to provide control signal for the flyback inverter to operate in synchronization with grid voltage, PV panel's voltage and current are provided to the MPPT controller to 
generate reference signal. To provide sinusoidal modulation, grid voltage is rectified and then multiplied by the reference signal, comparing its output with fixed sawtooth to generate converter control signal.

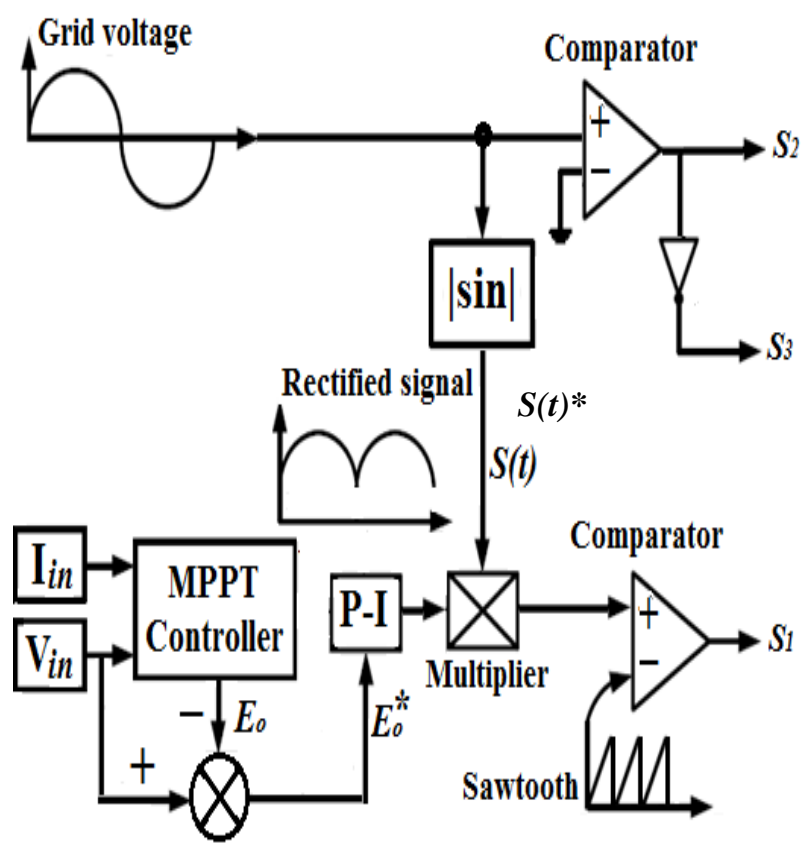

Figure (6): Proposed control circuit.

PV generation efficiency and power quality are the fundamental issues. PV power sources are usually integrated with control algorithms that have the task of ensuring maximum power point (MPP) operation. Many algorithms have been developed for tracking the maximum power point of a solar array [7-9].

Most commonly used are perturb and observe (P\&O) algorithm $[10,11]$ and the incremental conductance algorithm [12]. The main advantages of these algorithms are easy to build and low cost instruction. Consequently, researchers have been focused on the improvement of maximum-power-pointtracking (MPPT) control and the reduction of total harmonic distortion (THD). It is very important to design the MPPT control operation so that the voltage ripple at the terminals of the PV panel is a minimum. The Perturb and observe (P\&O) method also called "Hill-Climbing" is the most widely technique used for MPPT because of their simplicity and effectiveness. The perturbation in the operating voltage of the DC link between the PV array and the power converter is repeatedly done. In this method, $\mathrm{PV}$ power $\mathrm{P}(\mathrm{k})$ is measured and compared with the previous measured $\mathrm{PV}$ power $\mathrm{P}(\mathrm{k}-1)$. If the power increases, the same perturbation is applied in the same direction to get the next PV power otherwise perturbation is made in opposite direction. By this process, the operating point of the system gradually moves towards the MPP and oscillates around it. Based on these facts, the algorithm is implemented. The process is repeated until the MPP is reached [13]. $\mathrm{P} \& \mathrm{O}$ maximum power point tracking algorithm is used in this paper. Figure (7) shows the flowchart of the used MPPT control technique.

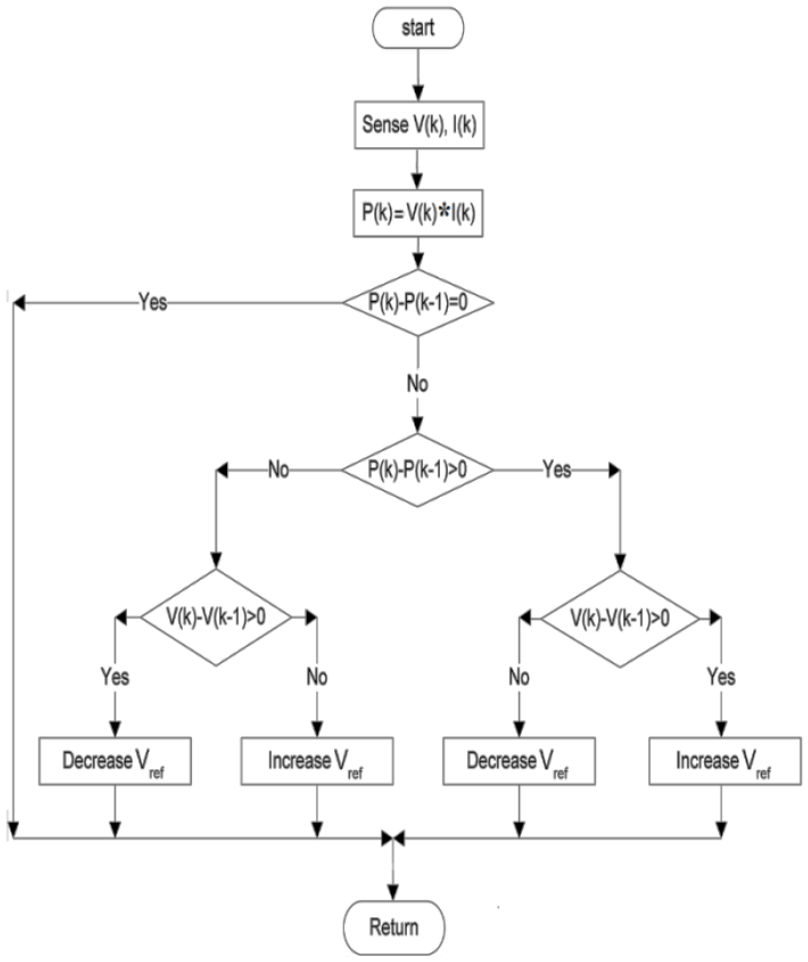

Figure (7): P\&O algorithm for MPPT

\section{SIMULATION RESULTS}

The proposed system as shown in Figure (8) is simulated using PSIM software. Table (1) shows the simulated system specifications. Figure (9) shows simulation result of the current fed to grid which is in-phase with the grid voltage with 0.9811 power factor and it has a low total harmonic distortion, which is $3.916 \%$ for $530 \mathrm{~W} / \mathrm{m}^{2}$, sunlight radiation. Figure (10-a) shows pulses of $S_{1}$ switch and Figure (10-b) and (10-c) shows pulses of flyback inverter switches $S_{2}$ and $S_{3}$. Figure (11) shows the primary current, as shown the current has a shape like a rectified sine this is due to sinusoidal modulation, the peak value of the $S_{1}$ current is $I_{p r i}=19.43 \mathrm{~A}$. Figure (12) shows the modulation signal $S(t)^{*}$ which is generated by multiplying the output of the proportionalintegral (P-I) controller by a rectified sine wave with unity amplitude. The P-I controller is used to regulate the output dc voltage of the MPPT controller. Figure (13) shows the PV output power. As shown in Figure (14) the output voltage of the PV panel is $V_{i n}=32.5 \mathrm{~V}$, Which is not pure dc voltage it has ripple value of $V_{\text {ripple }}=1 \mathrm{~V}$, however, any voltage ripple on the dc link will create distortion on the output current waveform, and increase the total harmonic distortion (THD).

In addition, the increased voltage ripple on the dc link introduces utilization losses on PV power. Therefore, a pure or low-ripple dc-link voltage is necessary. The main factor that causes the voltage ripple in single-phase grid-connected inverters is the instantaneous power fluctuation with a magnitude twice that of the average power and a frequency twice that of the grid frequency. Employing a power decoupling device is essential to filter this power fluctuation. Using a large electrolytic capacitor $\left(C_{d c}=10000 \mu \mathrm{F}\right)$ at the input is a simple method for power decoupling in flyback type microinverters [14, 15]. Figure (15) shows the PV output current, which it's value $I_{i n}=3.09 \mathrm{~A}$, and it has a little value of current ripple of $I_{\text {ripple }}=0.048$ A. Figure (16) show switches voltage stresses $S_{1}, S_{2}$ and $S_{3}$. As shown in these figures, all switches have lower stresses. On the other hand, it is clear that 
the modules operate at its maximum power. Figure (17) shows the switch $\mathrm{S}_{1}$ current $\left(I_{S I}\right)$ and $\mathrm{D}_{1}$ current $\left(I_{D I}\right)$ which shows that the diode $\mathrm{D}_{1}$ is on while the switch $S_{1}$ is not turns off, due to this a high spike voltage appears. Spike's voltage may damage the MOSFET and it should be reduced, this is done by adding a snubber circuit to the switch between the drain and source Figure (18-a) and (18-b) show switches $S_{2}$ and $S_{3}$ currents respectively . Figure (18-c) shows the ac output current before the output filter . Table (2) shows different values of power factor $\mathrm{P}$.F, THD and efficiency $\eta$, for $25^{\circ} \mathrm{C}$ temperature and different sunlight radiation values.
Table (1): System design specifications

\begin{tabular}{|c|c|c|c|}
\hline Parameters & Symbol & Value & unit \\
\hline Rated output power & $\boldsymbol{P}_{o(\max )}$ & $\mathbf{1 0 0}$ & $\mathrm{W}$ \\
\hline Switching frequency & $\boldsymbol{f}_{s}$ & $\mathbf{2 0}$ & $\mathbf{k H z}$ \\
\hline Grid voltage & $\boldsymbol{V}_{\text {grid_rms }}$ & $\mathbf{2 2 0}$ & $\mathrm{V}$ \\
\hline Input voltage & $\boldsymbol{V}_{\text {in }}$ & $\mathbf{2 2} \sim \mathbf{3 5}$ & $\mathrm{V}$ \\
\hline Grid frequency & $\boldsymbol{f}_{\text {grid }}$ & $\mathbf{5 0}$ & $\mathbf{H z}$ \\
\hline Total input capacitance & $\boldsymbol{C}_{\boldsymbol{d} c}$ & $\mathbf{1 0 0 0 0}$ & $\boldsymbol{\mu} \mathbf{F}$ \\
\hline Turns ratio of transformer & $\boldsymbol{N}$ & $\mathbf{0 . 2}$ & - \\
\hline Output filter capacitance & $\boldsymbol{C}_{f}$ & $\mathbf{3}$ & $\boldsymbol{\mu} \mathbf{F}$ \\
\hline Output filter inductance & $\boldsymbol{L}_{f}$ & $\mathbf{2}$ & $\mathbf{m H}$ \\
\hline Proportional constant gain & $\boldsymbol{k}_{p}$ & $\mathbf{0 . 5}$ & - \\
\hline Integral constant gain & $\boldsymbol{k}_{i}$ & $\mathbf{5 0}$ & - \\
\hline
\end{tabular}

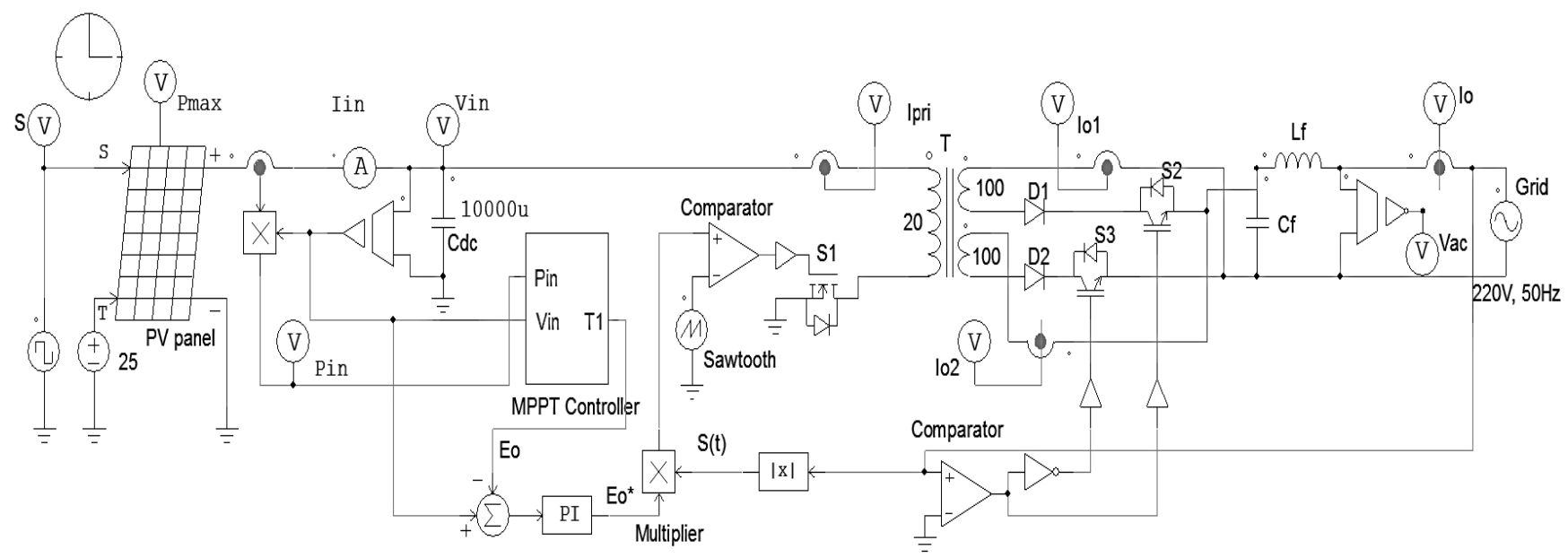

Figure (8): Proposed system simulation using PSIM program.

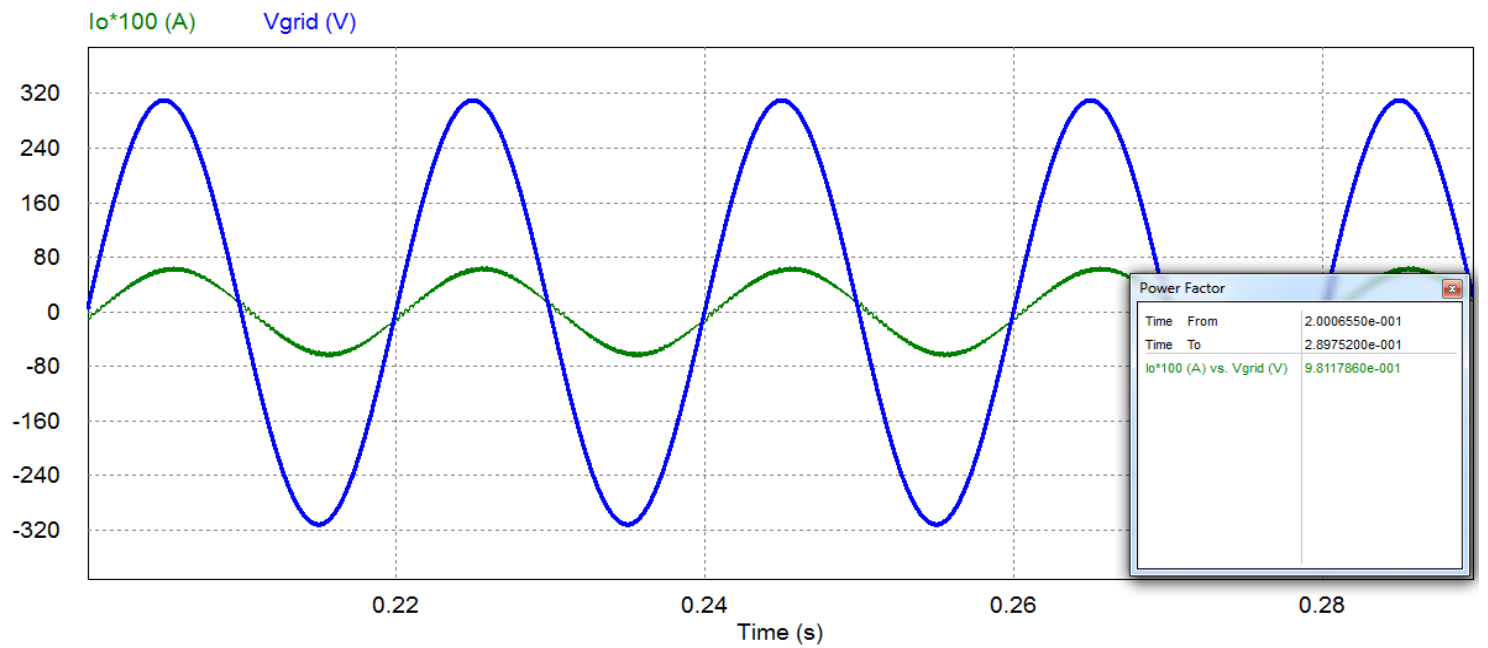

Figure (9): Current fed to grid multiplied by 100 and grid voltage. 


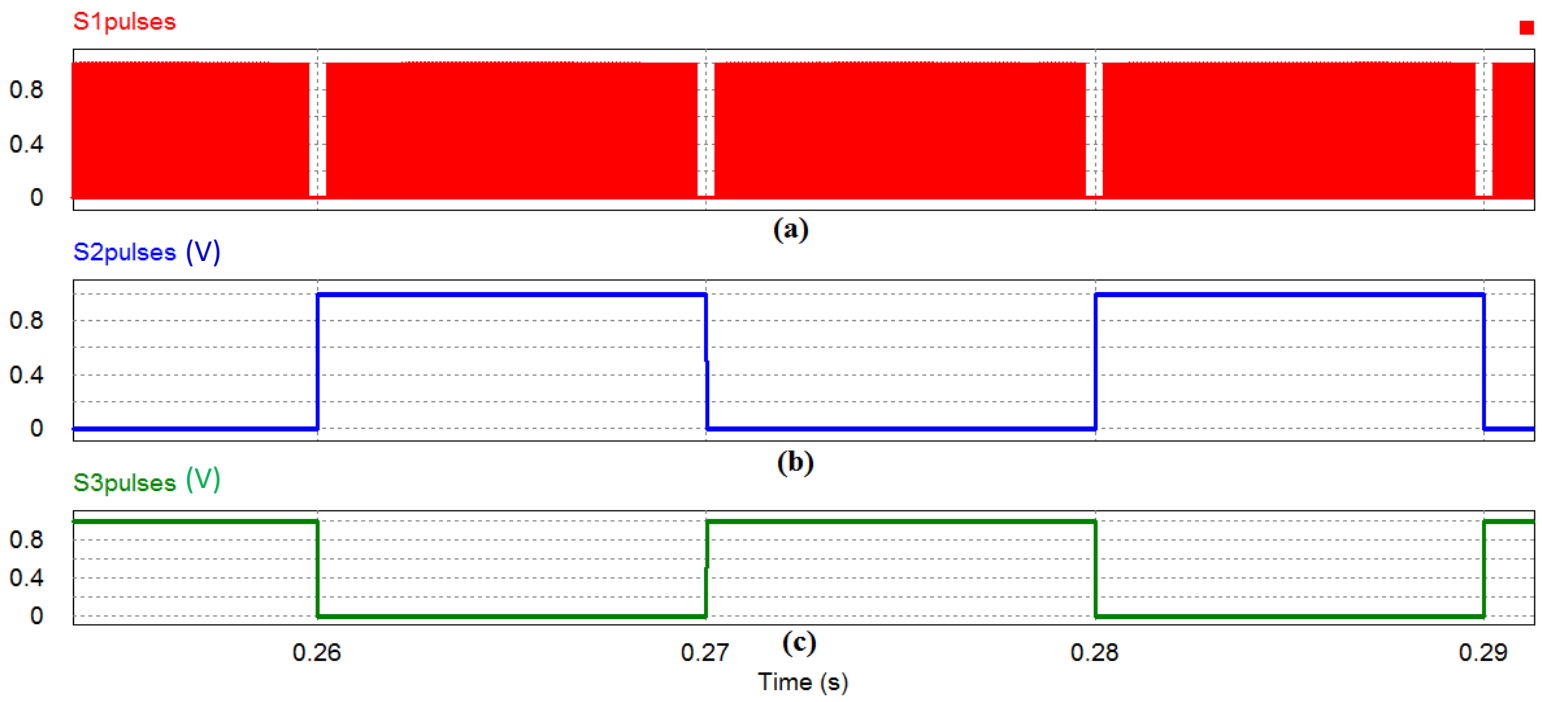

Figure (10): Switches pulses (a) Switch $S_{1}$ pulses. (b) Switch $S_{2}$ pulses. (c) Switch $S_{3}$ pulses.

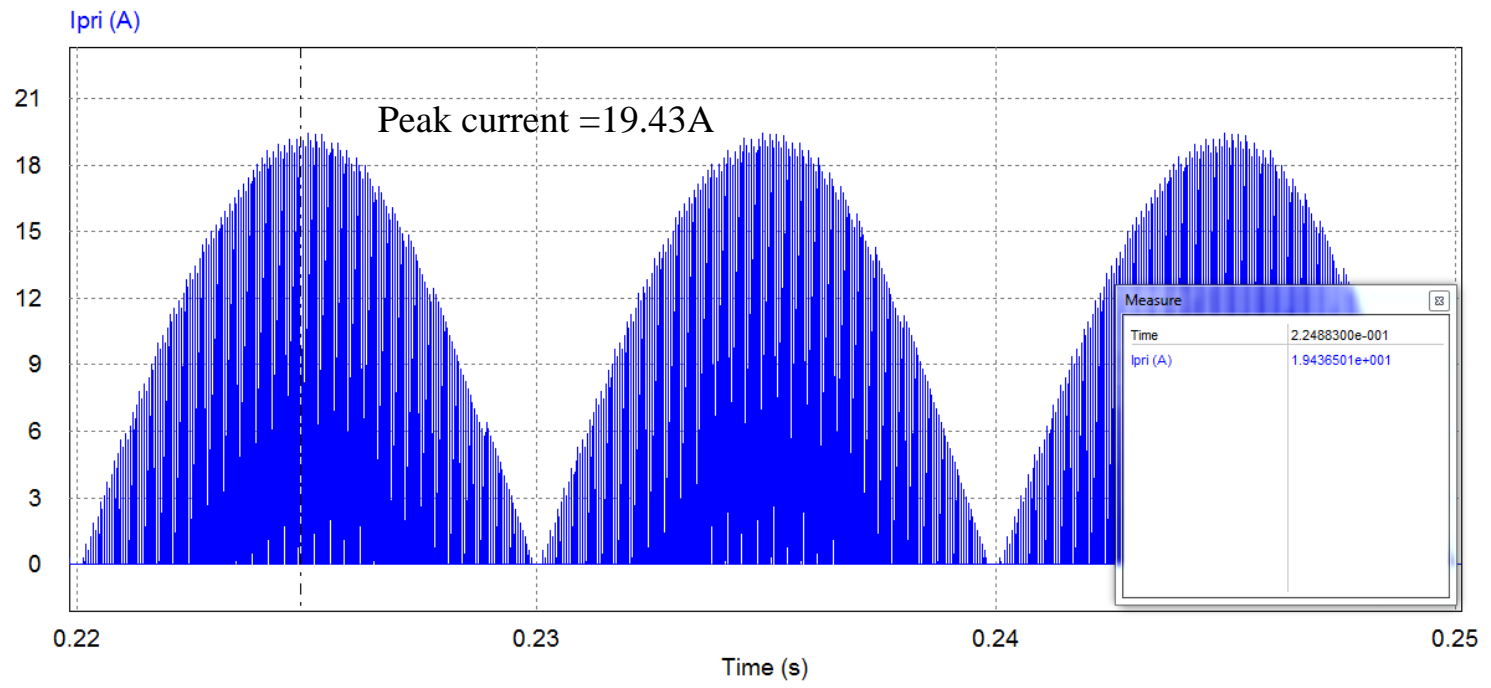

Figure (11): Primary current

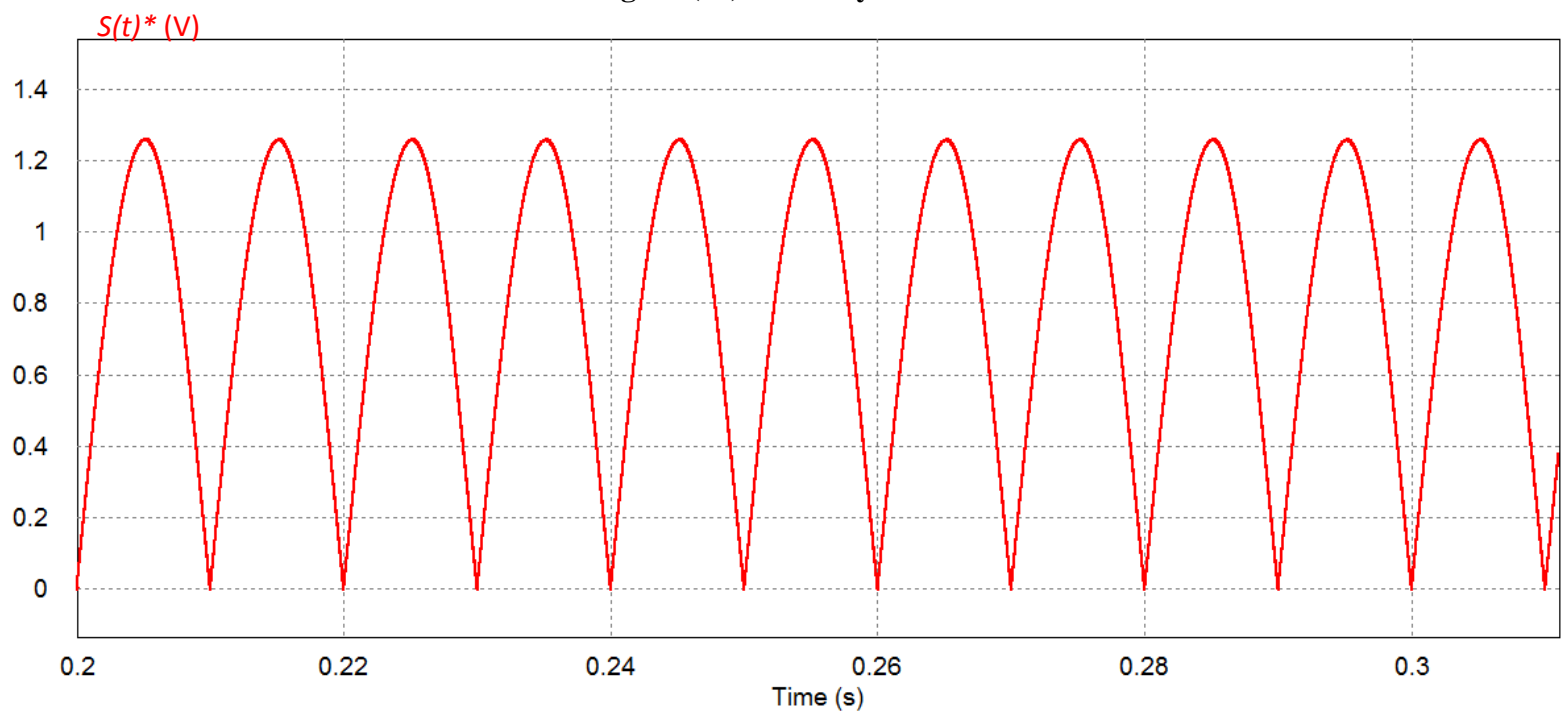

Figure (12): Modulation signal. 


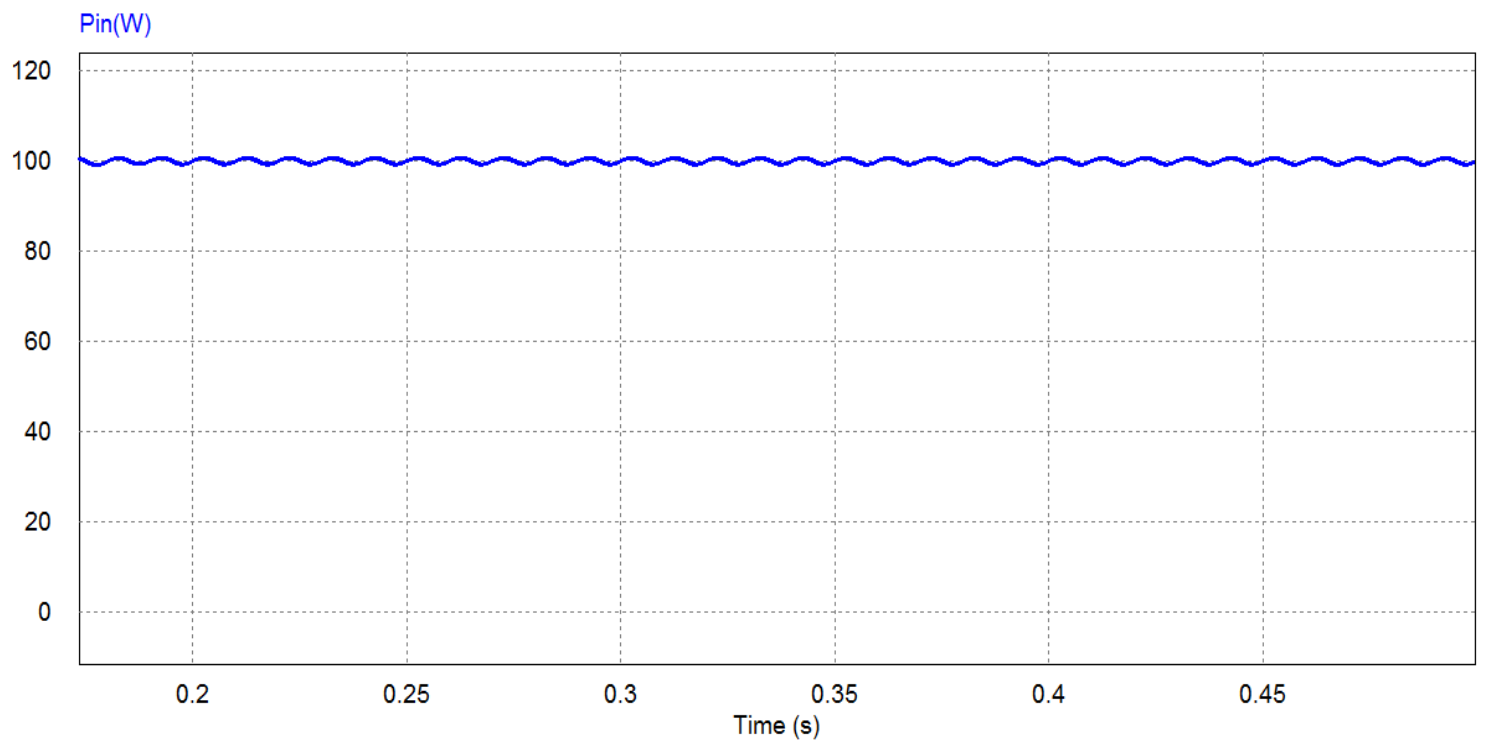

Figure (13): PV output power.

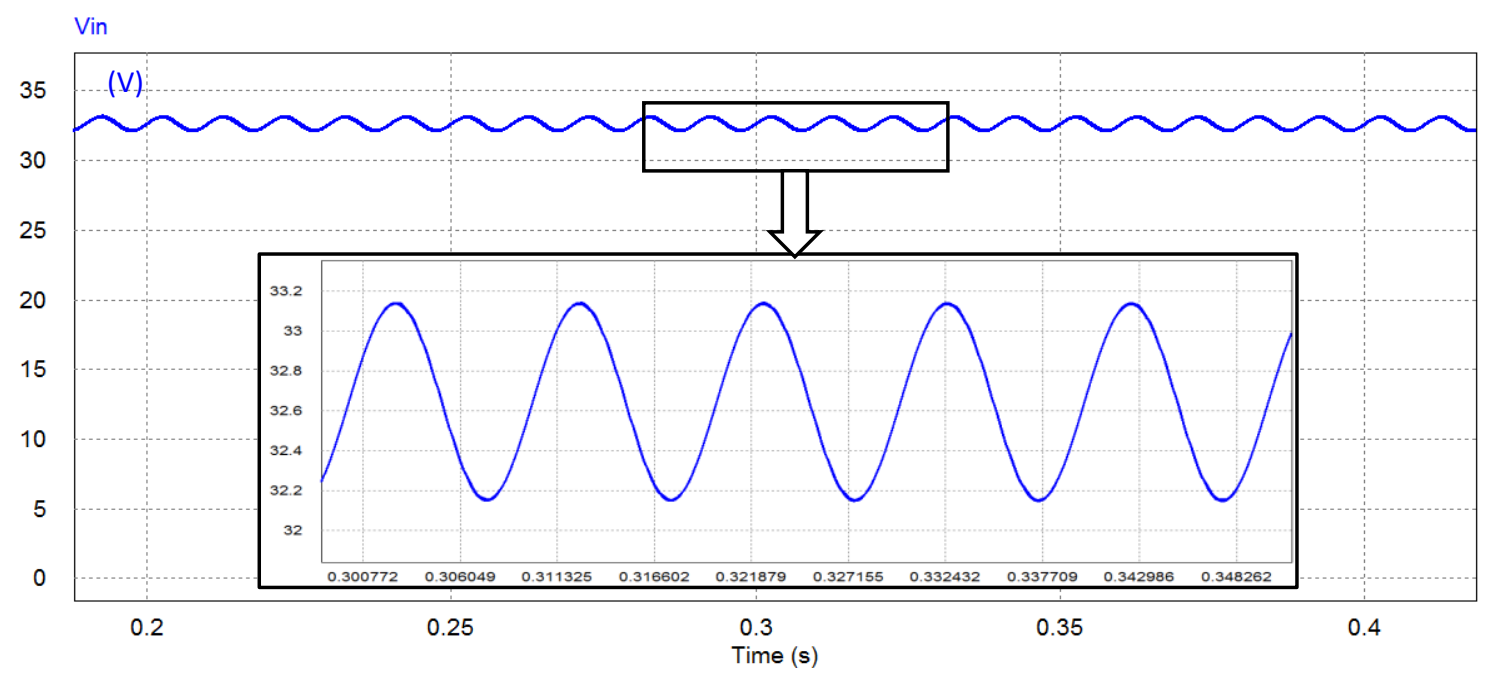

Figure (14): PV output voltage.

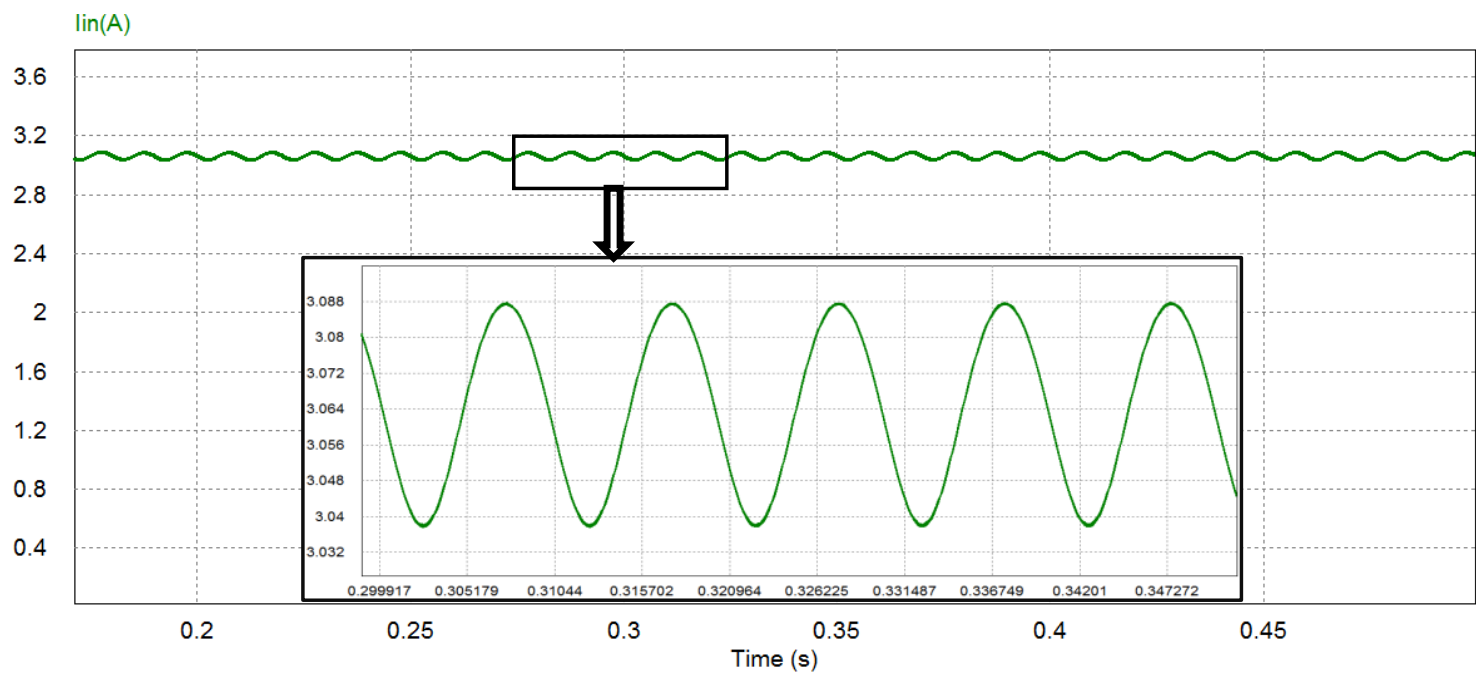

Figure (15): PV output current 

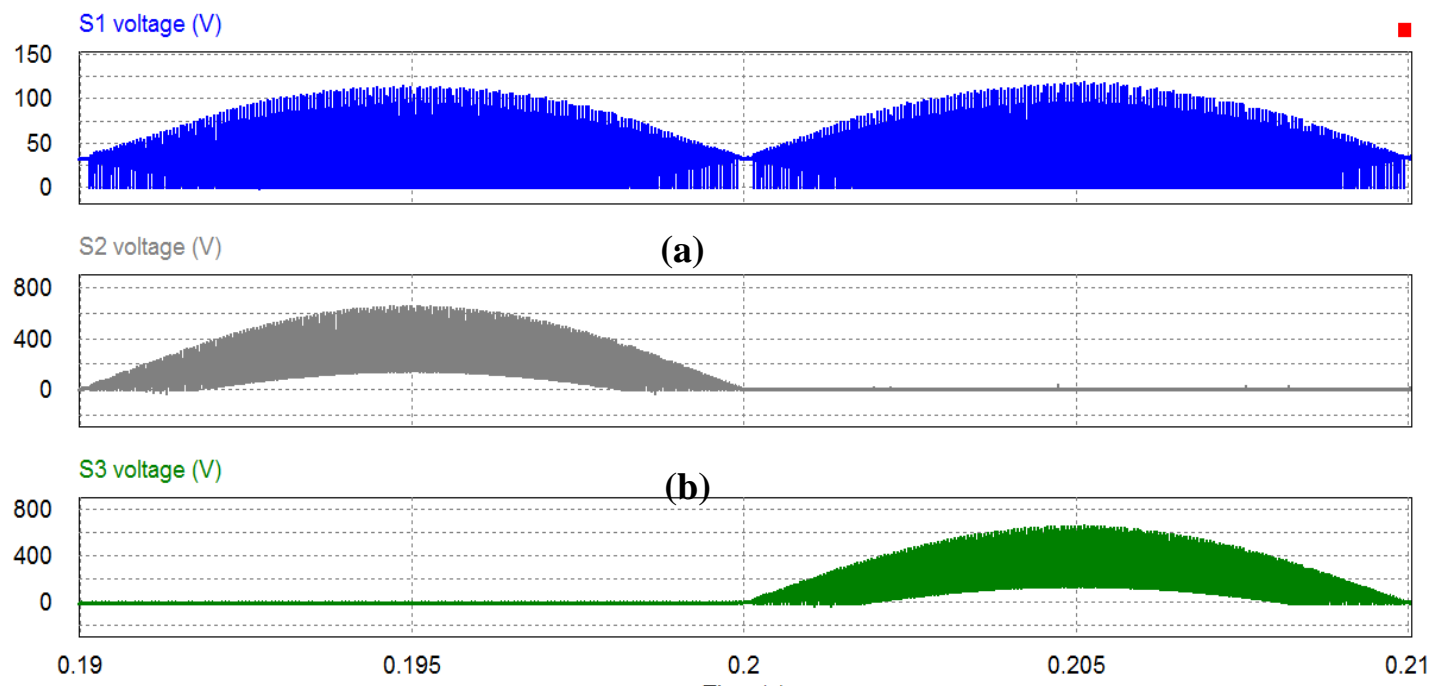

(c)

Figure (16): (a) Switch $S_{1}$ voltage. (b) Switch $S_{2}$ voltage. (c) Switch $S_{3}$ voltage.

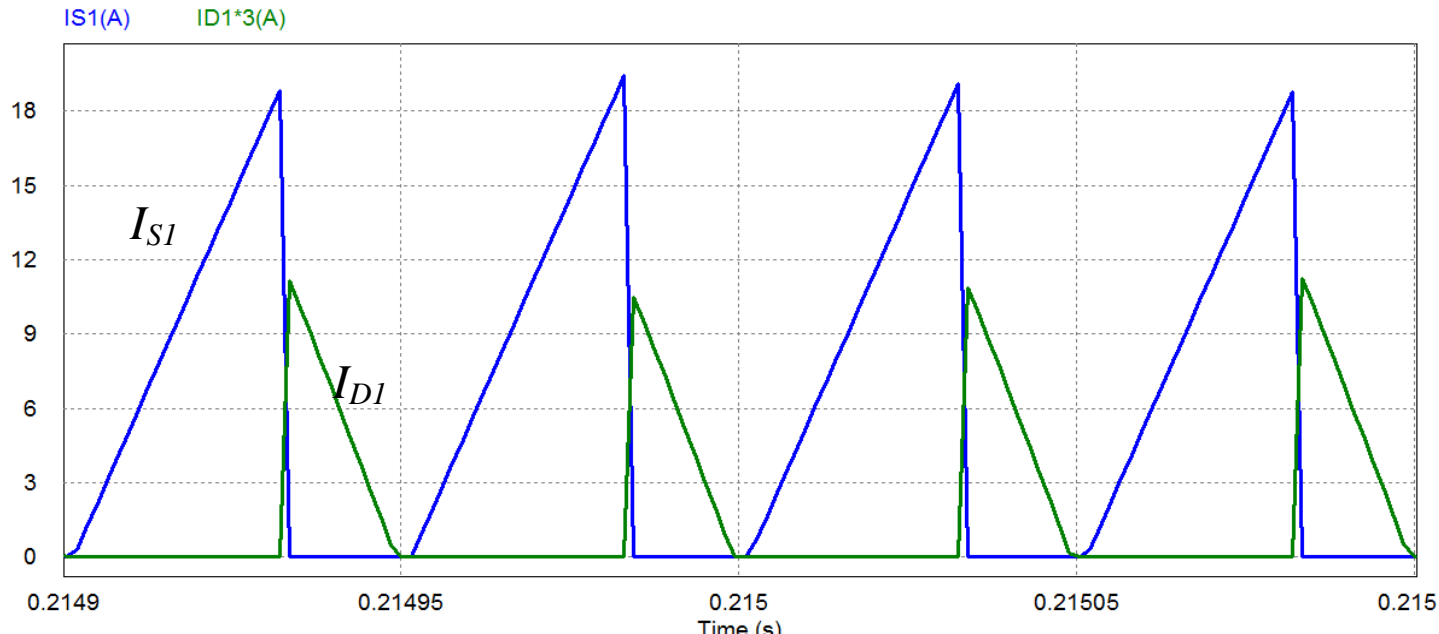

Figure (17): Switch $S_{1}$ current and diode $D_{1}$ current
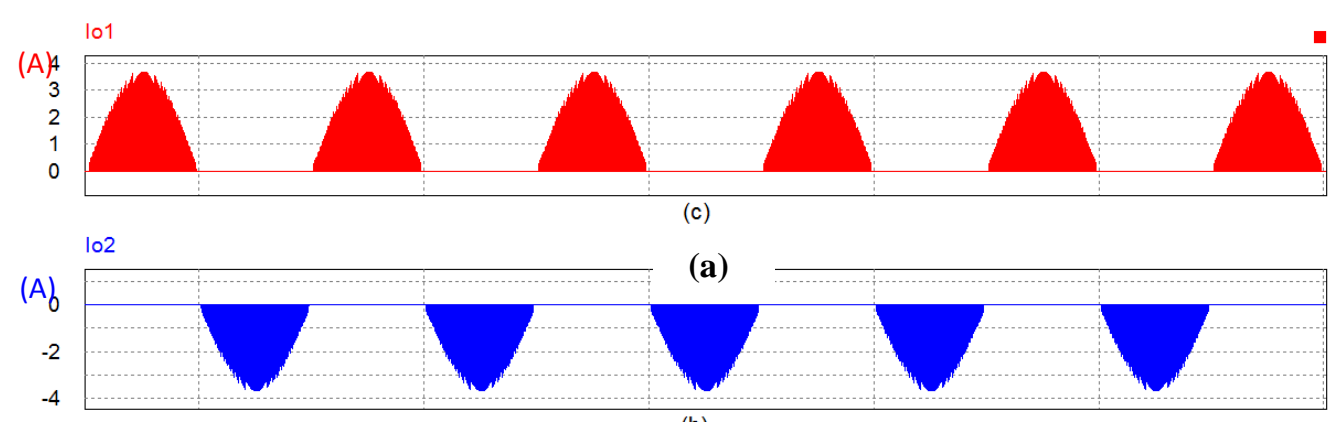

(b)

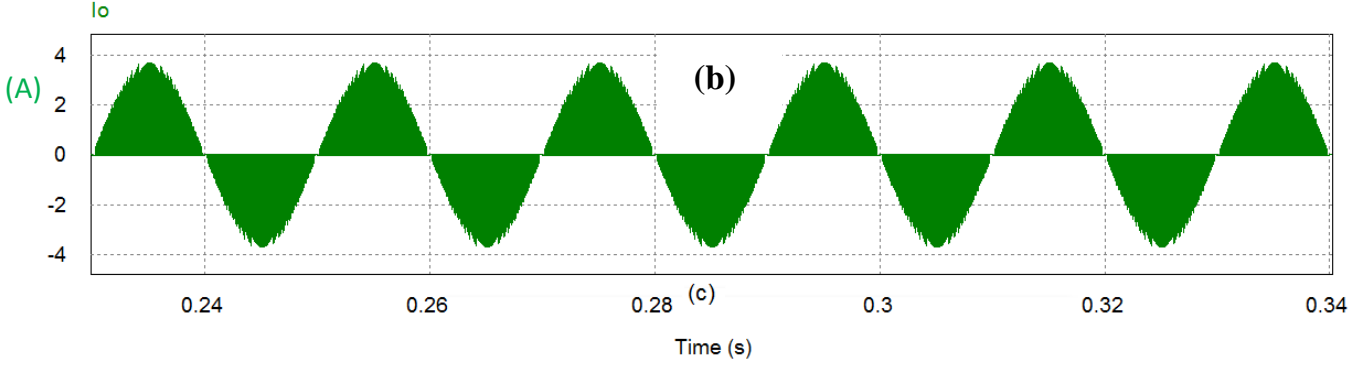

Figure (18): (a) Switch $S_{1}$ current. (b) Switch $S_{\text {. }}$ current. (c) Output current before filter.

(c) 
Table (2): Readings for different sunlight radiation

\begin{tabular}{|c|c|c|c|c|c|c|}
\hline $\mathrm{S}\left(\mathrm{W} / \mathrm{m}^{2}\right)$ & $\boldsymbol{P}_{\text {in }}(\mathbf{W})$ & THD (\%) & P.F & $I_{o_{\text {rms }}(\mathrm{A})}$ & $P_{o}(\mathrm{~W})$ & $\eta(\%)$ \\
\hline 530 & 100 & 3.916 & 0.98 & 0.439 & 94.6 & 94.6 \\
\hline 475 & 90 & 4.64 & 0.975 & 0.394 & 84.51 & 93.9 \\
\hline 425 & 80 & 4.77 & 0.969 & 0.35 & 74.61 & 93.2 \\
\hline 373 & 70 & 4.8 & 0.962 & 0.306 & 64.67 & 92.5 \\
\hline 322 & 60 & 4.92 & 0.952 & 0.264 & 55.29 & 92.2 \\
\hline 270 & 50 & 5.06 & 0.933 & 0.224 & 45.79 & 91.9 \\
\hline 218 & 40 & 5.22 & 0.905 & 0.184 & 36.63 & 91.5 \\
\hline 165 & 30 & 6.2 & 0.85 & 0.145 & 27.11 & 90.3 \\
\hline 112 & 20 & 6.8 & 0.665 & 0.117 & 17.11 & 85.5 \\
\hline
\end{tabular}

\section{CONCLUTION}

In this paper a single-stage grid-connected flyback microinverter operating in discontinuous conduction mode (DCM) is analyzed and simulated.

Based on simulation results, the following aspects can be concluded:

1. Sinusoidal output current injected into grid with approximately unity power factor is obtained.

2. The output power of the microinverter depends on the solar energy absorbed by photovoltaic panel, which is converted to electric energy. The maximum power point tracking algorithm (Perturb and Observe method) is used to extract the maximum power from the PV panel.

3. Low total harmonic distortion (THD) of output current is obtained due to the efficient control method and low-pass output filter (L-C filter).

4. The suggested flyback microinverter has high efficiency, high reliability and low cost due to single stage of dc-ac conversion.

An interleaved flyback microinverter operates in DCM can be used in order to increase the output power fed to the grid up to $200 \mathrm{~W}$.

\section{REFERENCES}

[1] S. B. Kjaer, et al., "A Review of Single-Phase GridConnected Inverters for Photovoltaic Modules", IEEE Transactions on Industrial Application, vol. 41, no. 5, pp. 1292-1306, Sep. 2005.

[2] D. C. Martins, and R. Demonti, "Photovoltaic Energy Processing for Utility Connected System", The 27th Annual Conference of the IEEE Industrial Electronics Society, pp. 1292 - 1296 vol.2, Denver, CO, (29 Nov.-02 Dec.), 2001.

[3] L. J. Sheng, "Power conditioning systems for renewable energies", International Conference on Electrical Machines and Systems, pp. 209 - 218, Seoul, Oct. (811), 2007.

[4] S. Jain and V. Agarwal,"A Single-Stage Grid Connected Inverter Topology for Solar PV Systems with Maximum Power Point Tracking", IEEE Transaction on Power Electronics, vol. 22, no. 5, pp. 1928-1940, Sep. 2007.

[5] O. Abdel-Rahim et al., "High Gain Single-Stage Inverter for Photovoltaic AC Modules", 26th Annual IEEE Applied Power Electronics Conference and Exposition (APEC), pp. 1961 - 1967, Fort Worth, TX, Mar. (6-11), 2011.
[6] T. Suntio et al., "Optimum Design of the Current-Source Flyback Inverter for Decentralized Grid-Connected Photovoltaic Systems", IEEE Transactions On Energy Conversion, vol. 32, no. 1, pp. 281-293, Mar. 2008.

[7] J. S. C. M. Raj and A. E. Jeyakumar, " A Novel Maximum Power Point Tracking Technique for Photovoltaic Module Based on Power Plane Analysis of I-V Characteristics", IEEE Transaction on Industrial Electronics, vol. 61, no. 9, pp. 4734 - 4745, Sep. 2014.

[8] C. Kalpana et al., "Design and Implementation of different MPPT Algorithms for PV System", International Journal of Science, Engineering and Technology Research (IJSETR), vol. 2, no. 10, pp. 1926 - 1933, Oct. 2013.

[9] D. P. Hohm and M. E. Ropp, " Comparative study of maximum power point tracking algorithms using an experimental, programmable, maximum power point tracking test bed", 28th Annual IEEE Photovoltaic Specialists Conference, pp. 1699 - 1702, Anchorage, AK, Sep. (15-22), 2000.

[10] N. Femia et al., "Optimization of Perturb and Observe Maximum Power Point Tracking Method", IEEE Transaction on Industrial Electronics, vol. 20, no. 4, pp. 963 - 973, Jul. 2005.

[11] A. M. Atallah et al., "Implementation of Perturb and Observe MPPT of PV System with Direct Control Method Using Buck and Buck-Boost Converter", Emerging Trends in Electrical, Electronics \& Instrumentation Engineering: An international Journal, vol. 1, no. 1, pp. 31 - 44, Feb. 2014.

[12] A. Safari and S. Mekhilef, "Simulation and Hardware Implementation of Incremental Conductance MPPT With Direct Control Method Using Cuk Converter", IEEE Transaction on Industrial Electronics, vol. 58, no. 4, pp. 1154 - 1161, Apr. 2011.

[13] S. Jain, et al., "Comparative Analysis of MPPT Techniques for PV in Domestic Applications", 6th IEEE Power India International Conference (PIICON), pp. 1 6, Delhi, Dec. (5-7), 2014.

[14] H. Hu, et al., "A Review of Power Decoupling Techniques for Microinverters With Three Different Decoupling Capacitor Locations in PV Systems", IEEE Transactions on Power Electronics, vol. 28, no. 6, pp. 2711-2726, Jun. 2013

[15] H. Hu, et al. " A Three-port Flyback for PV Microinverter Applications With Power Pulsation Decoupling Capability", IEEE Transactions on Power Electronics, vol. 27, no. 9, pp. 3953 - 3964, Sep. 2012. 